\title{
Photographic Assessment of Anterior Malar Eminence using Anterior Corneal Plane
}

\author{
1Javed Sodawala, ${ }^{2}$ Sayyed M Ali, ${ }^{3}$ Fatema Sodawala, ${ }^{4}$ Sumit Gandhi, ${ }^{5}$ Shaheen Hamdani, ${ }^{6}$ Deepkesh Bhuyan
}

\begin{abstract}
Aim: Vector relationship of the anterior corneal plane (ACP) and sella-nasion-orbitale (SNO) angle are used for assessing anteroposterior position of malar eminence. The purpose of this study was to evaluate the vector relationship of ACP and SNO angle and compare these parameters for assessing malar eminence.
\end{abstract}

Materials and methods: Forty study subjects (18 males and 22 females) aged 14-24 years without any craniofacial syndromes, facial asymmetries or a history of previous orthodontic treatment were randomly selected for this study. Vector relationship of ACP was evaluated on profile photographs and SNO angle was measured on lateral cephalograms. Pearson correlation coefficient was used to evaluate correlation between vector relationship of ACP and SNO angle.

Results: Sella-Nasion-Orbitale (SNO) angle was $5.08^{\circ}$ smaller in subjects with negative vector relationship as compared to subjects with a positive vector relationship of ACP. Also, there was highly significant correlation between $\mathrm{SNO}$ angle and vector relationship of ACP ( $p<0.001)$.

Conclusion: This study suggests that malar eminence is less prominent in subjects with a negative vector relationship as compared to a positive vector relationship of ACP.

Clinical significance: Vector relationship of ACP can be used to assess malar eminence on profile photographs.

Keywords: Anterior corneal plane, Malar eminence, SellaNasion-Orbitale angle, Vector relationship.

How to cite this article: Sodawala J, Ali SM, Sodawala F, Gandhi S, Hamdani S, Bhuyan D. Photographic Assessment of Anterior Malar Eminence using Anterior Corneal Plane. World J Dent 2018;9(6):513-516.

Source of support: Nil

Conflict of interest: None

\section{INTRODUCTION}

Mid-face plays an important role in the designing of macro-esthetics of the face. The skeletal structures of

\footnotetext{
1,2,4-6 Department of Orthodontics and Dentofacial Orthopedics, Rungta College of Dental Sciences and Research, Bhilai, Chhattisgarh, India

${ }^{3}$ Department of Prosthodontics and Crown and Bridge, Rungta College of Dental Sciences and Research, Bhilai, Chhattisgarh, India

Corresponding Author: Javed Sodawala, Department of Orthodontics and Dentofacial Orthopedics, Rungta College of Dental Sciences and Research, Bhilai, Chhattisgarh, India, e-mail: drjavedazher@gmail.com
}

the mid-face are difficult to identify on cephalograms. ${ }^{1,2}$ Malar eminence refers to the zygomatic or malar process of the maxilla. It is a rough triangular eminence situated at the angle of separation of the anterior, zygomatic and orbital surfaces where skin forms a gentle contour between the lower eyelid and the zygomatic bone.

A tangential line to the anterior surface of the cornea of the eye referred as an ACP has been suggested for assessing the malar eminence. ${ }^{3}$ The ideal projection of the malar eminence should be approximately $2 \mathrm{mms}$ beyond the ACP. ${ }^{4}$ Malar hypoplasia is associated with developmental disturbances such as cleft lip and palate, Treacher Collin's syndrome, Marfan syndrome.

Positive and negative vector relationship of ACP helps in the visual identification of the projection of cheek prominence in relation to the cornea and has been suggested as a new diagnostic tenet of the aesthetic mid-face for clinical assessment of anterior malar projection. ${ }^{5}$ The purpose of this study was to evaluate $\mathrm{SNO}$ angle and the vector relationship of ACP and compare both these parameters for assessing malar eminence.

\section{MATERIALS AND METHODS}

Forty subjects (22 females and 18 males) aged 14 to 24 years were randomly selected from the records available at Department of Orthodontics and Dentofacial Orthopedics of our institution for this study. Subjects with craniofacial syndromes, gross facial asymmetries or previous orthodontic treatment were excluded from the study. Before the commencement of this study, approval was obtained from ethics committee of the concerned institution. Standardized profile photographs were taken using Nikon D5100 SLR camera (Nikon Corporation, Japan) and standardized lateral cephalographs were taken using Orthophos XG (Sirona Dental Systems, Bensheim, Germany) by orienting the subjects in the natural head position.

Tracing of the profile photographs and lateral cephalographs was done on the matte acetate sheets. $\mathrm{ACP}$ was drawn by passing a line tangent to the cornea of the eye on the profile tracings. Vector relationship of ACP was assessed on profile photographs as positive or negative based on whether malar eminence is placed anterior or posterior to this plane (Fig. 1). Points sella $(\mathrm{S})$, nasion $(\mathrm{N})$ and orbitale $(\mathrm{O})$ were marked 
on cephalograph tracings. Malar eminence was also assessed in relation to anterior cranial base by measuring SNO angle on lateral cephalographs (Fig. 2). All measurements were done by a single examiner. Ten photographs and cephalographs were selected randomly and were traced and measured again after a week to check intra-examiner error.

\section{Statistical Analysis}

Data were collected and analyzed using the Statistical Package for Social Sciences (SPSS) software (version 19, IBM, Illinois, USA). Paired ' $t$ ' test was performed to evaluate gender differences with respect to age and SNO angle. Chi-square test was performed to evaluate gender differences with respect to the vector relationship of ACP. Correlation between SNO angle and vector relationship of ACP was determined by the Pearson correlation coefficient. Cohen's kappa coefficient was used to determine the intra-examiner error. The level of significance was set at $\mathrm{p}<0.05$.

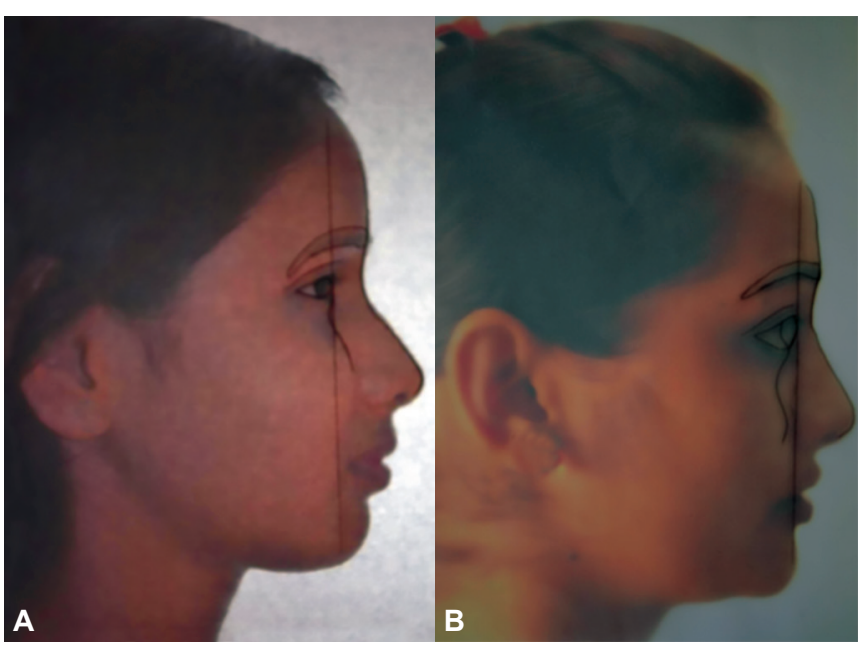

Figs. 1A and B: (A) Facial profile photographs showing positive vector relationship of anterior corneal plane; (B) Facial profile photographs showing negative vector relationship of anterior corneal plane

\section{RESULTS}

The mean age of subjects was $17.75 \pm 3.04$ years (Table 1 ). The mean SNO angle of subjects was $52.33 \pm 2.83^{\circ}$ (Table 2 ). Paired ' $\mathrm{t}$ ' test showed there were no significant gender differences ( $p>0.05$ ) with respect to age and SNO angle. Chi-square test showed there were no significant gender differences $(p>0.05)$ with respect to vector relationship of ACP (Table 3).

Therefore, the data of male and female subjects were combined as there were no significant gender differences with respect to age, $\mathrm{SNO}$ angle and vector relationship of ACP. Table 4 shows there was highly significant correlation ( $p>0.001$ ) between SNO angle and vector relationship of ACP. The value of Cohen's kappa coefficient was 0.84 suggesting low intra-examiner errors.

\section{DISCUSSION}

The vector relationship of ACP has been described as a diagnostic tool in the assessment of mid-face aesthetics which can be easily evaluated on profile photographs. ${ }^{5}$ This vector relationship was used to judge skeletal maxillary base support and was compared by means of SNO angle. In the present study, SNO angle was $5.08^{\circ}$ less in subjects with negative vector relationship when compared to subjects with positive vector relationship of ACP which was similar to the studies by Frey ${ }^{5}$ and Patil et al. ${ }^{6}$ This suggests that malar eminence was less prominent in subjects with negative vector relationship as compared to a positive vector relationship of ACP.

Anthropometric studies have shown that individuals with prominent malar bone have more youthful appearance whereas individuals with maxillary hypoplasia have been associated with a more aged look although some racial differences may occur. ${ }^{4}$ Miyajima et al. ${ }^{7}$ found that Japanese origin women have smaller midface lengths in comparison to European and American origin women.
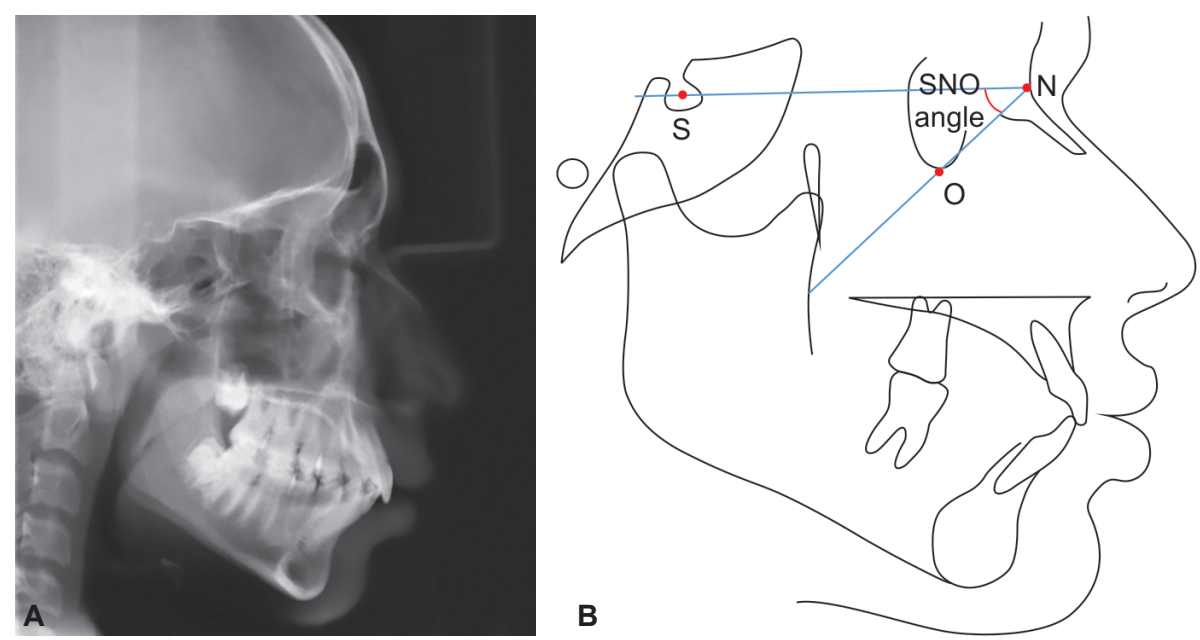

Figs 2A and B: (A) Digital lateral cephalogram of a study subject; (B) A cephalometric tracing showing SNO angle 
Photographic Assessment of Anterior Malar Eminence using Anterior Corneal Plane

Table 1: Descriptive statistics for age of the study subjects in years

\begin{tabular}{lllll}
\hline Age & $N$ & Range & Mean $\pm S D$ & $p$ \\
\hline Males & 18 & $14-23$ & $18.06 \pm 3.47$ & \multirow{2}{*}{0.101} \\
Females & 22 & $14-21$ & $17.50 \pm 2.69$ & \\
\hline Total & 40 & $14-23$ & $17.75 \pm 3.05$ & \\
\hline
\end{tabular}

$\mathrm{N}=$ Sample size, $\mathrm{SD}=$ Standard deviation

Table 2: SNO angle of the study subjects

\begin{tabular}{lllll}
\hline SNO angle & $N$ & Range & Mean $\pm S D$ & $p$ \\
\hline Males & 18 & $46-540$ & $51.80 \pm 2.410$ & \multirow{2}{*}{0.193} \\
Females & 22 & $48-580$ & $52.73 \pm 3.140$ & \\
\hline Total & 40 & $46-580$ & $52.33 \pm 2.830$ & \\
\hline
\end{tabular}

Table 3: Vector relationship of anterior corneal plane of study subjects

\begin{tabular}{lllll}
\hline Vector relationship & Positive vector & Negative vector & Total & $p$ \\
\hline Males & 14 & 4 & 18 & 0.499 \\
Females & 15 & 7 & 22 & \\
Total & 29 & 11 & 40 & \\
\hline
\end{tabular}

Table 4: Correlation between SNO angle and vector relationship of anterior corneal plane

\begin{tabular}{llllll}
\hline & Positive vector & Negative vector & & & \\
Vector relationship & Mean $\pm S D$ & Mean $\pm S D$ & Difference & ' $\delta$ 'value & Total \\
\hline SNO angle & $53.72 \pm 1.81^{\circ}$ & $48.64 \pm 1.20^{\circ}$ & $5.08^{\circ}$ & -0.681 & $<0.001$ \\
\hline
\end{tabular}

Mid-face structures change in anteroposterior dimensions as an infant's age increases. Bishara et al. ${ }^{8}$ found out that there was an increase in the SNA angle by $1.80^{\circ}$ with age. Mendelson et al. ${ }^{9}$ suggested that anterior maxillary wall retrudes in relation to bony orbit which maintains fixed anteroposterior dimension at its midpoint. This supports the use of SNO angle in the present study to assess anteroposterior position of malar eminence.

In the present study, a highly significant correlation was observed between SNO angle and vector relationship of ACP ( $p<0.001)$. Therefore, vector relationship of ACP as assessed on profile photographs can be used to assess the malar eminence in the same way as SNO angle on the lateral cephalographs.

Malar eminence and dentoalveolar segments have a remarkable influence in defining the nasal base lip contour. ${ }^{2} \mathrm{~A}$ negative vector relationship can be viewed as an indicator of regional skeletal dysplasia. Maxillary deficiency is variably manifest in infraorbital and paranasal regions, the canine fossae, the malar eminences and the upper lip. ${ }^{10}$

Nartallo-Turley and Turley ${ }^{11}$ found a forward movement of orbitale by $2 \mathrm{~mm}$ in patients undergoing facemask therapy. It shows that if regional skeletal dysplasia is diagnosed early, maxillary protraction can be advised. Jose et al. ${ }^{12}$ found out significant improvement in the malar projection in individuals undergoing face mask protraction therapy, although, it did not change a negative vector relationship to positive vector relationship of ACP in these individuals.

Malar eminence is usually not affected by orthodontic treatment, but over retraction of maxillary teeth can cause flattening around this region. ${ }^{13}$ Therefore, during treatment planning, the importance must be given to the position of upper incisors, extractions of teeth if needed, and anchorage considerations to avoid any undesired results.
The position of the globe of the eye can affect the vector relationship of ACP. If the globe of the eye is too forwardly place it can result in negative vector relationship. In such cases, the cause of exophthalmos can be inflammatory, neoplastic, cystic, vascular or traumatic. ${ }^{14}$ Similarly, the soft tissue thicknesses of the cheek may mask the true skeletal dysplasia and can affect this relationship. Also, the relative position of the soft tissues changes with age. Although, it remains unclear what relative part soft-tissue changes and skeletal changes play in the aging face. Relative to the globe, the facial skeleton appears to rotate such that the frontal bone moves anteriorly and inferiorly while the maxilla moves posteriorly and superiorly. ${ }^{15}$

Further studies should evaluate the long term age changes of malar eminence and vector relationship of $\mathrm{ACP}$ in the same individuals. Also, 3D imaging techniques should be used in the future studies for better bilateral landmark identification and determination of vector relationship of ACP.

\section{CONCLUSION}

The SNO angle in subjects with a negative vector relationship of ACP was less by $5.08^{\circ}$ suggesting less prominent malar eminence as compared to positive vector relationship subjects. A highly significant correlation was found between SNO angle and vector relationship of ACP. Therefore, the vector relationship of ACP can be used to assess the malar eminence on profile photographs.

\section{REFERENCES}

1. Arnett GW, Bergman RT. Facial keys to orthodontic diagnosis and treatment planning. Part I. Am J Orthod Dentofacial Orthop 1993;103:299-312.

2. Arnett GW, Bergman RT. Facial keys to orthodontic diagnosis and treatment planning. Part II. Am J Orthod Dentofacial Orthop 1993;103:395-411. 
3. Jelks G. The influence of orbital and eyelid anatomy on the palpebral aperture. Clin Plast Surg 1991;18:183-195.

4. Yaremchuk M. Infra-orbital rim augmentation. Plast Reconstr Surg 2001;107:1585-1592.

5. Frey ST. New diagnostic tenet of the aesthetic mid-face for clinical assessment of anterior malar projection. Angle Orthod 2013;83:790-794.

6. Patil BC, Dave P, Patil V, Patil K, Bellam S, Anjali V. Evaluation of diagnostic criteria for clinical assessment of anterior malar projection in relation to midface esthetics. Int $\mathrm{J}$ Recent Sci Res 2007;8:17018-17022.

7. Miyajima K, McNamara JA, Kimura T, Murata S, Iizuka T. Craniofacial structure of Japanese and European American adults with normal occlusions and well balanced faces. Am J Orthod Dentofacial Orthop 1996;110:431-438.

8. Bishara SE, Peterson LC, Bishara EC. Changes in facial dimensions and relationship between the ages of 5 and 25 years. Am J Orthod Dentofacial Orthop 1984;85:238-252.

9. Mendelson BC, Hartley W, Scott M, McNab A, Granzow JW. Age related changes of orbit and midcheek and the implications for facial rejuvenation. Aesthetic Plast Surg 2007;31:419-423.
10. Budhiawan M, Anggani HS. Considerations before orthodontic camouflage treatment in skeletal Class III malocclusion. Padjadjaran J. Dentistry 2008;20:23-33.

11. Nartallo-Turley PE, Turley PK. Cephalometric effects of combined palatal expansion and facemask therapy on Class III malocclusion. Angle Orthod 1998;68:217-224.

12. Jose J, Nelivigi N, Pai SS, Pai V, Vishwanath AE, Prasad M, Suhas. Validity of visual vector relationship for the clinical assessment of anterior malar projection and the changes observed in facemask therapy patients- A retrospective study. IOSR-JDMS 2016;15:143-148.

13. Ismail SFH, Moss JP, Hennessy R. Three-dimensionalassessment of the effects of extraction and nonextractionorthodontic treatment on the face. Am J Orthod Dentofacial Orthop 2002;121:244-256.

14. Garner A. Pathology of 'pseudotumours' of the orbit: A review. J Clin Path 1973;26:639-648.

15. Richard MJ, Morris C, Deen BF, Gray L, Woodward JA. Analysis of the anatomic changes of the aging facial skeleton using computer assisted tomography. Ophthal Plast Reconstr Surg 2009;25:382-386. 